\title{
The Senior Living Lab: an example of nursing leadership
}

\author{
This article was published in the following Dove Press journal: \\ Clinical Interventions in Aging \\ 29 February 2016 \\ Number of times this article has been viewed
}

\author{
Susie Riva-Mossman \\ Thomas Kampel \\ Christine Cohen \\ Henk Verloo \\ School of Nursing Sciences, La \\ Source, University of Applied Sciences \\ and Arts of Western Switzerland, \\ Lausanne, Switzerland
}

Correspondence: Susie Riva-Mossman School of Nursing Sciences, La Source, University of Applied Sciences and Arts of Western Switzerland, Lausanne, 30, Avenue Vinet, 1004 Lausanne, Switzerland

$\mathrm{Tel}+4|2| 64 \mid 3867$

Fax+4I 21 6413810

Email su.riva@bluewin.ch

\begin{abstract}
The Senior Living Lab (SLL) is dedicated to the care of older adults and exemplifies how nursing leadership can influence clinical practice by designing research models capable of configuring interdisciplinary partnerships with the potential of generating innovative practices and better older patient outcomes. Demographic change resulting in growing numbers of older adults requires a societal approach, uniting stakeholders in social innovation processes. The LL approach is an innovative research method that values user perceptions and participation in the cocreation of new products and services. The SLL is crafting a platform responsive to change. It is a learning organization facilitating community-based participatory research methods in the field. Advanced nurse practitioners are well positioned to lead the way forward, fostering interdisciplinary academic collaborations dedicated to healthy aging at home. The SLL demonstrates how nursing science is taking the lead in the field of social innovation.
\end{abstract}

Keywords: community-based participatory approach, Living Lab, nursing leadership, nursing practice, Senior Living Lab, social innovation

\section{Background}

The inevitable consequences of the demographic transition resulting from fertility decline and increased longevity referred to as population aging, the process by which older individuals become a proportionally larger share of the total population, require a coordinated response. ${ }^{1,2}$ The societal phenomena of a rapidly increasing aging population has a profound impact on public health and economic, political, and social conditions. ${ }^{3}$ Population aging is inextricably linked with socioeconomic development. While aging presents challenges to society, it also creates many opportunities. Fostering good health in older age is central to the global response to population aging.

Healthy aging in Europe is a declared health care priority. ${ }^{4}$ The current demographic changes that European countries are facing require a rapid approach integrating social innovation that increases the collective capacity to respond by increasing the efficiency of innovation phases and developing technologies, products, and services to meet the needs of the aging population. Aging is interrelated with other major global trends such as urbanization, technological change, and globalization. ${ }^{5}$ Reinventing aging (changing social attitudes to encourage the participation of older people) implies transforming the current narrative. Many current attitudes to aging were developed during the twentieth century when there were far fewer older people and when social patterns were very different. ${ }^{6}$ These outdated conceptions limit our capacity to identify the real challenges, and to seize the opportunities, of population aging in the twenty-first century. ${ }^{5}$ We need to envision and develop new models of aging that will help us create the future society in which we want to live. ${ }^{5}$ 
Societal challenges in health care are influencing the need for interdisciplinary approaches. ${ }^{3}$ The European Union is eliciting a holistic societal reflection, funding research, and developing models of best practice. ${ }^{7}$ Leadership approaches dovetail with care needs, configuring new collaborations between advanced nursing practitioners, interdisciplinary research teams, and stakeholders, orienting research, regional responses, and practice. ${ }^{8}$

Our societal challenge goes beyond developing new forms of care. It implies envisioning a bright future. Carstensen $^{9}$ mentioned in his recent publication that there is a danger that lies ahead for our society is that by failing to creatively and proactively adjust to life span changes. The author also mentions we will condemn the old people of the future to live like the old people of the past, even though they will be healthier, more mentally agile, and capable of doing much more. ${ }^{9}$

Assuring, a bright future means redesigning the expectations inherent in traditional life spans. Society, and especially nurses, must think differently about aging, so that older people can act differently, remaining active and leading fulfilling lives in later life. ${ }^{3}$ Professional perceptions of aging contribute to this transformation by actively contributing to storying a positive narrative on aging. Kerlinger $^{6}$ mentions that nurses, by structuring the nursing knowledge in nursing theories (unique, borrowed, and shared theories), are able to construct a set of interrelations, definitions, and propositions that present a systemic view of societal challenges by clarifying relations among stakeholders. By introducing the five core components of nursing knowledge (metaparadigm, philosophy, conceptual models, nursing theories, and empirical indicators), nurses are able to develop interdisciplinary and interprofessional cooperation. This form of collaborative practice integrates both substance and process. ${ }^{10}$

Recently, following the lead of nurses, an interdisciplinary and interprofessional research project was developed in a Living Lab (LL) configuration dedicated to older adults in Western Switzerland. ${ }^{11}$ This article discusses the challenges and the growing opportunity for nurses to assume a leading role in interdisciplinary research projects engendering social innovation.

\section{Senior Living Lab: a social learning space lead by social artists}

The Senior Living Lab (SLL) is an interdisciplinary research project uniting multiple faculties within the University of Applied Sciences and Arts Western Switzerland ${ }^{11}$ (Table 1).
Table I Aim of the Senior Living Lab

A social laboratory developing multiple forms of social innovation by using participatory methods and generating a new life-course vision for and with older adults

The concept originated from nursing faculty, initiating research funding, and coordinating the interdisciplinary research project. Other researchers from the Universities of Applied Sciences in design, engineering, and business all participated in the research design phase that was successfully able to secure funding from the Gerbert Rüf Stiftung Foundation ${ }^{12}$ (Table 2).

The SLL is a social learning space fostering encounters among colearners. Their inquiry is contained in a social space and place of practice where participants are vehicles for "knowledgeability". ${ }^{13}$ The Universities of Applied Sciences in Western Switzerland followed the lead of experienced highly educated nurses, convening a community learning citizenship initiative, building social learning capability, and fostering innovation potential within the social system. Wenger $^{14}$ describes social artists as leaders occupying an organizational space inspiring creativity and followership. The learning process is activated through their dynamic and holistic participation. Their leadership style infuses the team relationships with an optimistic social vision capable of eliciting a focused approach. These leaders are able to communicate and share their passion and courage while facing societal challenges.

The SLL's first artifact is its interdisciplinary research approach, offering an experiential learning experience. Cocreating qualitative needs assessment methods generates an academic know-how that is transferable to other LL (Table 3). Learning within the SLL is distinguishable from more traditional pedagogies taught within formal learning institutions. It differs from other LLs by involving older adults in the conception of the research activities.

The social construction of aging and the images and narratives pertaining to aging influence the performance of growing old on the stage of life. Action research can

Table 2 The interdisciplinary research team of the Senior Living Lab

- Seniors

- Designers

- Economists

- Computer engineers

- Nurses

- Psychologists

- Mediators 
Table 3 Methodologies of the Senior Living Lab

Ecological model ${ }^{39}$

$\mathrm{CPBR}^{55}$

Living Lab method ${ }^{56}$ (coconstruction workshops with business partners, active seniors, virtual platform: www.seniorlivinglab.ch)

Nursing sciences ${ }^{8}$ (transitional care, $[\ldots]$ )

Interdisciplinary research approach

Qualitative research methods

- Social constructionist approaches (World Café methodology)

- Narrative inquiry

- Ethnography (video, focus groups, semistructured interviews)

- Action research

Quantitative research methods

- Needs assessment with validated tools and patient chart reviews

Abbreviation: CPBR, community-based participatory approach.

contribute to the art of growing old, opening up new and as yet unforeseen possibilities through social innovation. Codesigning future social space with interdisciplinary research partners and senior participants has the potential of conceiving new landscapes of meaning in a collective "life-scaping". A necessary shift in mindset about learning is needed as we face the demographic challenge before us. Wenger ${ }^{14}$ mentions that the combination of practical experiments and conceptual framework is an urgent need today when the world is full of pressing large-scale learning imperatives and will give the models we need to accelerate the learning of our small planet.

The SLL is a model leading social innovation in the nursing sciences, engendering new collaborations, products, and services for healthy aging. Participatory research methods contribute by bringing democratic principles into health care through citizen involvement. Nursing sciences can actively participate in shaping the future of aging by playing a leadership role, initiating new forms of collaborative research and practice, crafting health care platforms, and enabling elders to age-at-home (Figure 1).

\section{Transformational leadership facilitating interdisciplinary research: the example of SLL}

Nursing knowledge capital in care is positioning the nursing sciences in a leadership role that is defining action research approaches aimed to improve aging persons care. ${ }^{8}$ In this context, leadership is considered the ability to influence team members to work toward meeting shared goals. ${ }^{15}$ Nurses are exercising their leadership skills more than ever in today's rapidly changing health care system ${ }^{8}$ (Table 4 ). As nurses are recognized as team leaders within interdisciplinary care continuums, nursing professionals become well positioned to initiate care innovation. ${ }^{8}{ }^{85}$ Kaufman ${ }^{16}$ declares that leadership is not just about changing things, it is about changing the world.

The LL model and methodology is particularly relevant in this context, as it fosters an interdisciplinary and interprofessional approach, coconstructing solutions for societal issues. ${ }^{17,18}$ User contribution distinguishes the LL model from other approaches by taking into account what users adopt (Figure 2). ${ }^{19}$

New leadership models are needed to elicit collaboration, share understanding, and joint action.

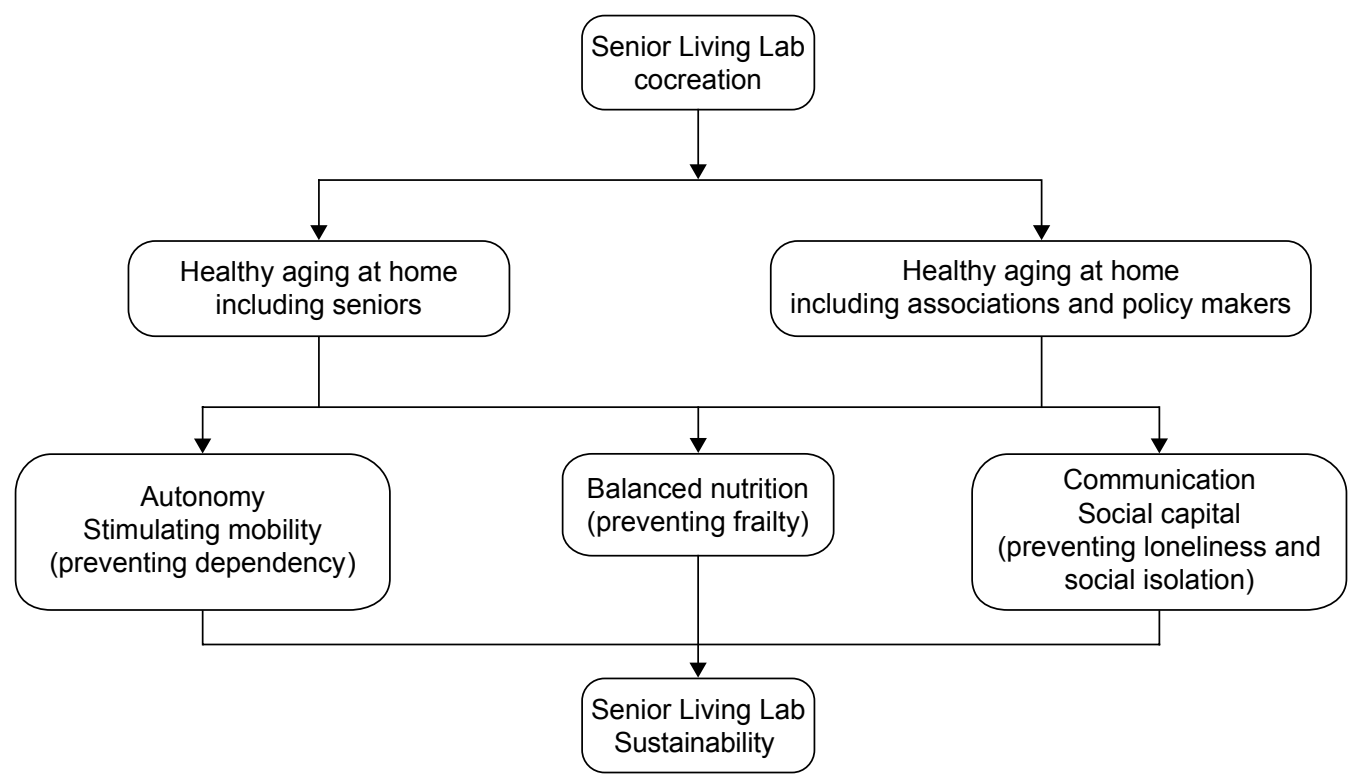

Figure I Strategy of the Senior Living Lab. 
Table 4 Examples of growing knowledge in geriatric nursing, relational approach to health aging, and leadership changes

I. Examples of growing knowledge in geriatric nursing:

- Expertise in comprehensive geriatric assessment

- Evidence-based practices and guidelines in care of older adults

- Interprofessional collaboration in palliative care and delirium assessment

- Frailty assessment and intervention strategies

- Management of behavioral and psychological symptoms of dementia 2. Relational approach to healthy aging

- Forging and maintaining supportive social relationships and proactive engagement:

- Developing social network and opportunities

- Nurturing relationships with family members

- Volunteer activities

- Cultivating faith

- Constructing a trustful relationship with a primary care physician/ provider

- Regularly visits to primary health care provider

- Healthy and nutritious diet

- Regular nights sleep

- Regular exercise to increase stamina

- Intellectual stimulation (crossword or Sudoku puzzles)

- Spend time with Mother Nature

- Consider holistic medicine

3. Some examples of leadership changes capable of adapting to societal challenges

\section{Current focus}

Hierarchical leadership

Horizontal development

Leadership resides in

individual managers

Top-down management

approach
Creating such a context also entails integrating communities in the organization - giving them a voice in decisions and legitimacy in influencing operating units, and developing internal processes for managing the value they create. ${ }^{13}$

Transformational leadership (TFL) has been particularly effective in the coconstruction of the SLL. ${ }^{20}$ TFL can be defined as a way of being that encourages team members to contribute in a form of participatory leadership, codefining goals, and transforming individual interests into shared group goals and action plans, encompassing the larger group vision. ${ }^{21}$ This approach is based on an inspirational capacity able to engage team members in a shared vision with the potential of transcending traditional research frameworks, providing a creative space to coconstruct interdisciplinary and interprofessional research that can respond to demanding societal challenges (Figure 3). TFL was particularly suited in the coconstruction phase of the SLL, striving for effective communication, empowerment, and team commitment. ${ }^{22}$

\section{Fostering knowledgeability}

There is a form of professional upward mobility as new higher education $\mathrm{PhD}$ programs are designed and developed, encompassing a broader vision of an interdisciplinary and interprofessional collaboration. This has only recently been an option in Western Switzerland. ${ }^{23}$ This evolution in the organization of higher education in geriatric nursing has created new skills and

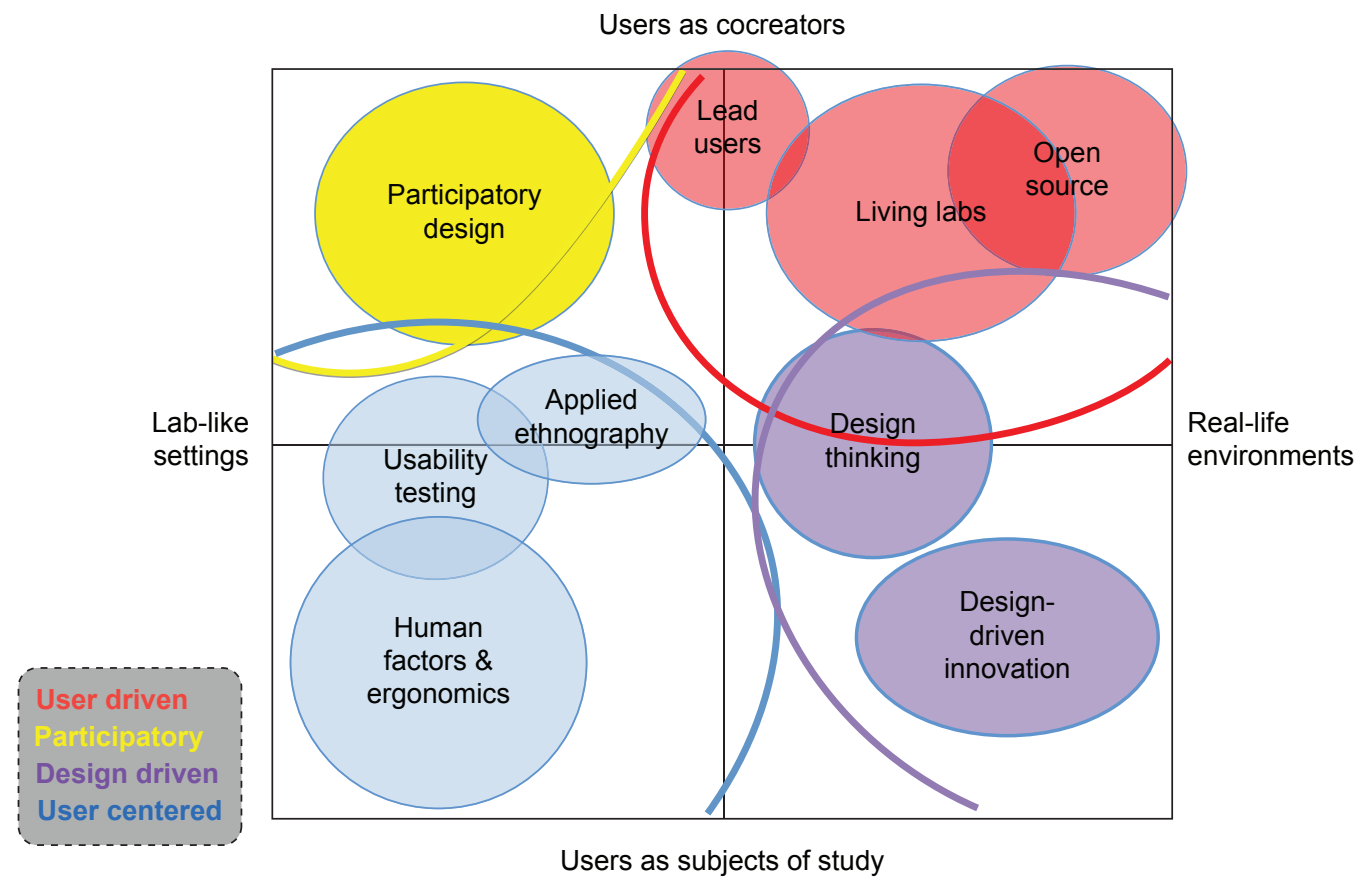

Figure 2 Living Lab and customer/user innovation approach. ${ }^{19}$

Note: We thank Almirall E, Lee M, Wareham J for allowing the use of Figure 2. Reproduced from Almirall E, Lee M, Wareham J. Mapping living labs in the landscape of innovation methodologies. Technology Innovation Management Review. 2012;2(9):12-18.19 


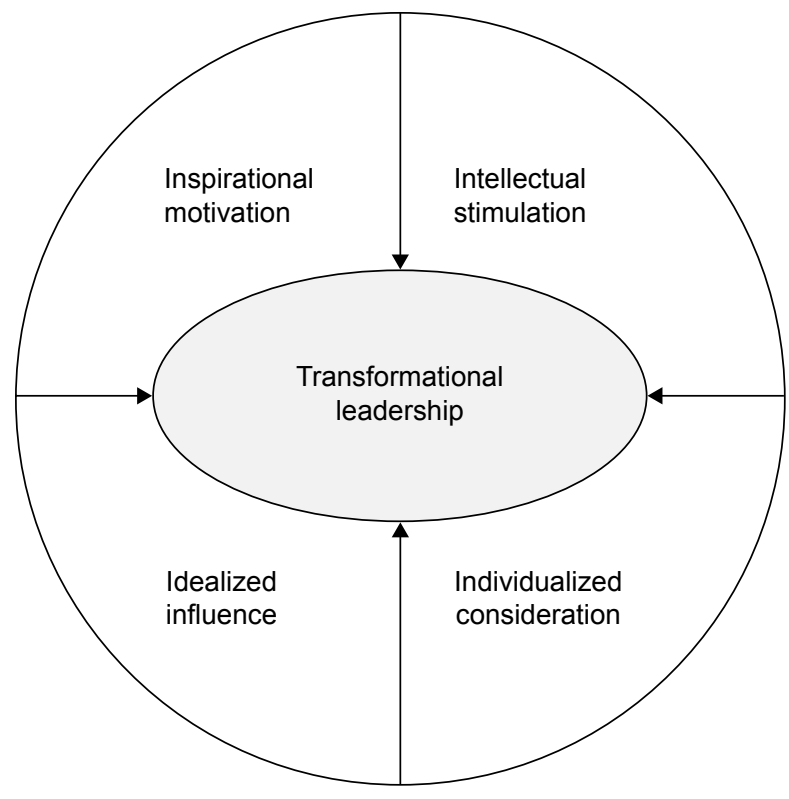

Figure 3 Components of transformational leadership. Notes: Data from Dionne et al. ${ }^{22}$

greater recognition for the nursing sciences within the larger university faculties and larger academic community. ${ }^{20}$

Many nursing science journals have been created, stimulating the participation of nursing professionals in the development of scientific methods and scientific writing, adding to the growing body of knowledge in the field. ${ }^{10}$ This knowledgeability is orienting the future of care. Nursing's growing knowledge capital in the geriatric nursing practices has greatly contributed to this new positioning of the nursing sciences, allowing nursing to enter the academic circle with advanced practices and nursing research, actively participating in the coconstruction of interdisciplinary health care. ${ }^{5}$

The SLL is an interesting case study, demonstrating the impact higher education in nursing can have on interdisciplinary research models, applying the LL approach to healthy aging in Europe. Latimer ${ }^{24}$ evokes clearly that a field does not exist but rather is constructed by the way in which it is thought by a research project. This way of thinking connects nursing and health care in the way it is being imagined - to the assumptions and taken-for-granted ideas that underpin a research study. ${ }^{24}$

This "new paradigm" in geriatric nursing contributes to rethinking the field and reconfiguring the relations within the new space, cocreating physical and social environments that foster the health and participation of older people. ${ }^{5}$

\section{Interprofessional practice and collaborative continuums}

Transitional care has become an important concept in health care. ${ }^{5,25}$ Collaborative continuums configuring the different phases of care offered to fragile and vulnerable aging people require a form of intermediation. ${ }^{26,27}$ Interdisciplinary platforms allow health care professionals to integrate new approaches and new technologies known as gerontechnologies in relation to care. ${ }^{28}$ The successful integration of these technological innovations into the home environment requires the participation of users. ${ }^{17,29}$ Aging people, and both their family and professional care providers, are consulted in the development process through research projects using needs assessment to give voice to senior needs. The LL model offers an approach valuing user perceptions. ${ }^{29}$ The process of bringing together stakeholders and users, within a collaborative platform, has been a central guiding strategy influencing the governance of the SLL.

A life-course vision in health care is emerging eliciting a holistic, intergenerational approach to demographic change. ${ }^{1}$ However, this "life-course" vision of health care requires increased collaboration between professionals and academia. ${ }^{25}$ Interdisciplinary education, interprofessional cooperation, and collaborative practice all require a reconfiguration of academic blueprints, fostering collaboration on multiple levels. This transformation is a fundamental requirement blazing the trail for social innovation. Nursing sciences can benefit from this transition by taking the lead in research design and interprofessional practice including older adults, and codesigning new best practices to meet future needs. ${ }^{30}$ Evidence-based practice requires increased academic experience and participation in research design to inform practitioners in the field and shape new ways of going on together. ${ }^{31}$ Producing scientific papers is a way of participating in the knowledge production process. ${ }^{32}$ Nursing sciences can this way collaborate with other disciplines, valuing their own discipline's expertise while cultivating academic collaborations that open up new possibilities in the field. This interdisciplinary nursing approach benefits from the implication of the social sciences, providing a methodological framework capable of generating transformative, collaborative practices. ${ }^{33}$

\section{A relational approach to healthy aging}

Within this emerging field of inquiry, the importance of relationships has been studied yielding proof that relational coordination improves patient care. Gittell ${ }^{33}$ explains in a recent publication when doctors, nurses, therapists, case managers, social workers, other clinical staff, and administrative staff are connected by shared goals, shared knowledge, and mutual respect, their communication tends to be more 
frequent, timely, accurate, and focused on the problem solving enabling them to deliver cost-effective, high-quality patient care.

Health care can be improved by using the power of relationships, working to assure quality, efficiency, and resilience. However, a global vision of healthy aging is needed, underscoring prevention early in life so that older aging people can fully appreciate the years that have been added on to Western European life spans. Still, these relationships are not solely within the traditional health care environment. There is a global movement creating platforms of technology and know-how that can be procured by municipalities eager to improve the quality of life of their citizens. This citizen-centric approach to wellness is a growing movement throughout Europe.

Cities must respond to the demands of the knowledgebased economy, while facing the societal and environmental challenges that threaten their own long-term sustainability. "To be sustainable in the 21 st century, a city must not only embrace environmental challenges, it must also address systemic economic and societal issues". ${ }^{34}$ This new vision of connectivity enables citizens to have access to services that allow for communities to cocreate societal, environmental, and economic sustainability. This systemic view of services for citizen well-being is configuring expectations for healthy aging in Europe. ${ }^{35}$ Municipalities and communities are increasingly responsible for providing integrated services to their citizens.

\section{Coconstructing social innovation methods}

The SLL allows for cross-pollination within the circles of collaborative clusters, valuing user and professional perspectives. Innovation spirals cultivate a culture of reciprocity by integrating the voices of both designers and users. Needs assessment performed by researchers, seniors, and community representatives, jointly collecting data during community events, provides a community-based approach with qualitative action research methods. ${ }^{36} \mathrm{~A}$ catalog of activities allows the interdisciplinary team and the community and public health officials to codesign individualized field research models. The World Café method ${ }^{37}$ and other events in each municipality can be configured to meet the needs of each regional organization participating in the SLL approach (Table 3).

Nurses with clinical experience in cognitive deficiencies are able to cocreate an interdisciplinary response to demographic change and the increased needs of the aging in our society. ${ }^{8}$ The LL methodology (Figure 2) provides a research model linking designers and users in the social innovation process. ${ }^{17}$ The codesign of the interdisciplinary methods draws from social constructionist approaches. ${ }^{38}$ This relational and ecological approach, coconstructing the action research field-space, gives value to regional needs. ${ }^{39}$

A multimethod model weaves together several key methodological approaches (Table 3). First, an ecological approach to research design was chosen, giving priority to regional community needs. ${ }^{39}$ Community-based participatory practice provided a blueprint for health care research concerned with the needs of vulnerable members of the community. ${ }^{40}$ It was also chosen for its ability to give voice to vulnerable members of society, using research as a form of social agency working for sustainable social justice. In this case, the voices of the aging have been integrated by creating a senior advisory council. ${ }^{41}$ Social constructionist methods valuing transformative and generative practices were equally adopted. ${ }^{42}$ Appreciative inquiry was used to imagine a hopeful future, eliciting a collaborative response to future needs. ${ }^{43}$ Narrative inquiry allowed for user and professional needs to be collected through the questioning process. ${ }^{44}$ Ethnographic methods, like photo-voice, were used to gather pictures and films to inform the focus groups, eliciting enriching community conversations about healthy aging. ${ }^{36}$

Gergen's vision of research takes the position that inquiry is a form of collaborative and social action, "it is time for the social sciences to channel their substantial resources of intelligence and ingenuity into creating more flourishing forms of living together". ${ }^{38}$ The SLL serves as a space of intermediation for all of these converging academic approaches. As the interdisciplinary team enters the field of research, social innovation is fostered through community conversations around health care, generating new ideas and insights that allow for the harvesting of diverse forms of social innovation. The SLL applies concepts and methods within a living social environment, aware that new technologies, products, and services cannot take hold unless they are designed with the collaboration of users, hence the importance of senior participation and mentorship.

The LL model is well suited to integrate multiple methods of data collection in the needs assessment phase. Traditional ethnographic methods and social constructionist approaches simultaneously elicit social innovation within the greater social and health care network by opening up dialogical space and collecting user perceptions. 


\section{Leadership capable of adapting to societal challenges}

Meeting future needs implies designing future organizations capable of rapid adaptation to evolving societal challenges. Learning organizations capable of continual reflection and renewal provide an organic web of social relations, connecting local communities with larger global visions. The WHO's report on Friendly Cities for the Aging provides a global vision articulating goals for healthy aging. ${ }^{45}$ International research stresses the importance of lifestyle and nutrition; these healthy living preventive approaches throughout the life course are fundamental components of well-being. ${ }^{46}$ Transportation systems linking the aging to community centers and services are a proven factor contributing to wellness, by combating social isolation. This suggestion underpins that older adults who are able to withstand socially isolating circumstances or adjust their expectations so that they do not develop a subjective sense of isolation may fare better, with respect to physical and mental health, than those who feel isolated. This statement corroborates with the findings of Cornwell and Waite. ${ }^{47}$

The advancement of smart-living home design offers a protective net, reinforcing social connectedness, preventing accidents, and offering alarm systems to be activated in case of falls or other home-related accidents. Staying connected is a priority for vulnerable elders who are often living alone with different forms of disabilities. ${ }^{48}$

Mapping resources and defining regional platforms of cooperation contribute to the creation of a regional coherence espousing a life course vision. Disease prevention is recognized as the most effective way of assuring healthy aging as stated by Prince et al. ${ }^{46}$ Increased longevity is often correlated with increasing care needs, as aging people are confronted with disabilities and vulnerability associated with longer life spans reaching up to 100 years of age. Cultivating awareness of global policy among interprofessional teams responsible for regional health care networks requires new skills. ${ }^{49}$ Traditional professional roles are transformed as interdisciplinary collaboration reconfigures collaborative continuums. Regional collaborative clusters come together within the SLL; a social innovation model with a virtual platform connecting stakeholders. Global and local meet in a "glocal" approach to social innovation, crafting platforms, and reconfiguring care, with the LL tool kit.

Health care informed by evidence-based practice and implemented through educational processes is lead today by highly educated nursing science PhD's who have gained academic research skills, informing the future of care..$^{10,31}$
The coconstruction of societal health care solutions can benefit from this growing know-how in care. "Nursing processes emanate from persons, groups, and communities and are by their nature relational, contextual, and transformative". ${ }^{50}$

The SLL promotes and encourages the participation of municipalities and districts referred to as cantons that often are responsible for implementing health care policy. Regions must prepare for transportation and housing development that are adapted to senior needs. Governments are challenged to adjust financial planning to support longer retirement periods. Lifelong learning projects allowing seniors to keep abreast of changing technologies and infrastructures all support the unfolding of a hopeful future. Civil society is also an important stakeholder. Through the lobbying of retired persons in national organizations like the FARES (Fédération des Associations des retraitées et de l'entraide en Suisse), ${ }^{51}$ Federating Regional Aging People's Associations, the voice of the aging is structured in a way that allows them to be heard by politicians, advocating for legislation changes, and the protection of elder rights.

The WHO highlights the important relational interface between hospitals and communities. ${ }^{52}$ Building relational and communicational platforms can prevent hospitalizations for elders by assuring their chronic care services with multiple innovations designed to support their well-being and safety. Care integrates new treatment methods with prevention and social connectedness; accentuating the role of intermediation within the SLL.

\section{An epigenetic paradigm engendering a new narrative on aging}

The SLL gathers voices from many different perspectives, writing a narrative on aging that offers a hopeful future. As aging people are able to live well longer, healthy aging can transform the human narrative, rewriting the archetypical metaphors associated with the life course. The components of healthy aging lead us to the conclusion that health prevention must begin at conception. New medical paradigms introducing epigenetics provide a transformed lens for understanding how genetic influence combines with perception and environment, influencing genetic expression. Our perception of aging and our societal narrative influence how we will perform aging in the future.

The SLL aims to unite communities in an ecological approach to healthy aging by inviting stakeholders to participate in regional World Cafés, using participatory approaches to community needs assessment and diagnosis, allowing 
imaginings of new life-course trajectories to emerge in a form of societal transformation.

For Randall and McKim, ${ }^{53}$ the word "growing" suggests the generative, life-giving force present in the meaningmaking process storying the "life course". But even in later life, our life story is, technically, still unfolding. The End has not yet been written, which means that we lack the benefit of parameters on what, in the interim, the meaning(s) of our story might be. ${ }^{53}$

As we write our individual life story, we are part of a larger metanarrative.

Our perceptions of aging configure the metanarrative on aging. In "Rembrandt's Mother praying" painted in the early 1600 s, a wrinkled face with hands pressed in prayer associates aging with contemplation. This period's representation of older people contributed to the definition of their social expressions and social actions in the sociocultural field just as today; ageism continues to influence how elders are seen and hence, how they see themselves, and how they know to behave. This interdependence between individual and social processes alludes to a significant component: lifelong learning. ${ }^{54}$ Learning processes are at the core of transformative societal processes where social learning spaces meet with individual trajectories. ${ }^{13}$ Humanity can learn to age positively espousing a transformed aging narrative.

\section{Acknowledgments}

We thank our partners Luc Bergeron, Nathalie Nyffeler, Elena Muggelini, Delphine Roulet Schwab, and Nataly Viens Python for their participation in this research project. We also thank the University of Applied Sciences Western Switzerland, ECAL, Lausanne, Switzerland, the University of Applied Sciences Western Switzerland School of Business and Engineering, Yverdon, Switzerland, and the University of Applied Sciences Western Switzerland School of Engineering and Architecture, Fribourg, Switzerland for their contribution. This research project was funded in part by Gebert Rüf Stiftung and the University of Applied Sciences Western Switzerland School of Nursing La Source, Lausanne, Switzerland.

\section{Author contributions}

All authors contributed toward data analysis, drafting and critically revising the paper and agree to be accountable for all aspects of the work.

\section{Disclosure}

The authors report no conflicts of interest in this work.

\section{References}

1. World Health Organisation. Good Health Add Live to Years: Global Brief for World Health Day 2012. Geneva, Switzerland: WHO; 2012.

2. European Commission. Economic and Budgetary Projections for the 28 EU Member States (2013-2060). Brussels, Belgium: European Commission; 2015.

3. Beard JR, Bloom DE. Towards a comprehensive public health response to population ageing. Lancet. 2015;385(9968):658-661.

4. Joint Programming Initiative. More Years, Better Lives - A Strategic Research Agenda on Demographic Change. Brussels, Belgium: Joint Programming Initiative; 2014.

5. Moyle W, Parker D, Bramble M. Care of Older Adults: A StrengthsBased Approach. Sydney, Australia: Cambridge University Press; 2014.

6. Kerlinger FN. Foundations of Behavioral Research. 3rd ed. New York, NY: Holt, Rinehart and Winston; 1986.

7. Stegeman I, Otte-Trojel T, Costongs E, Considine J. Healthy and Active Ageing. Brussels, Belgium: EuroHealthNet; 2012.

8. Blair KA, Jansen MP. Advanced Practice Nursing: Core Concepts for Professional Role Development. 5th ed. New York, NY: Springer Publishing Company; 2015.

9. Carstensen LL. A Long Bright Future: Happiness, Health, and Financial Security in an Age of Increased Longevity. 2nd ed. New York, NY: Public Affairs; 2011.

10. Fawcett J. The state of nursing science: hallmarks of the 20th and $21 \mathrm{st}$ centuries. In: Cody WK, editor. Philosophical and Theoretical Perspectives for Advanced Nursing Practice. 5th ed. Burlington, MA: Jones \& Bartlett Learning; 2013:35-42.

11. seniorlivinglab.ch [homepage on the Internet]. Senior Living Lab. 2015. Available from: http://www.seniorlivinglab.ch/. Accessed June 4, 2015.

12. grstiftung.ch [homepage on the Internet]. Gebert Rüf Stiftung. 2015. Available from: http://www.grstiftung.ch/en.html. Accessed June 6, 2015.

13. Wenger-Trayner E, Fenton-O’Creevy M, Hutchinson S, Kubiak C, Wenger-Trayner B. Learning in Landscapes of Practice: Boundaries, Identity, and Knowledgeability in Practice-Based Learning. 1st ed. New York, NY: Routledge; 2015.

14. Wenger E. Social learning capability: four essays on innovation and learning in social systems. In: Boddington A, Boys J, editors. ReShaping Learning: A Critical Reader. Rotterdam, the Netherlands: Sense Publishers; 2011:193-210.

15. Yoder-Wise PS. Leading and Managing in Nursing. 5th ed. St Louis, MO: Elsevier Mosby; 2011.

16. Kaufman N. Changing economics in an area of healthcare reform. J Healthc Manag. 2011;56(1):9-13.

17. Ståhlbröst A, Holst M. The Living Lab Methodology Handbook. Luleå, Sweden: Luleå University; 2012.

18. Bergvall-Kåreborn $\mathrm{B}$, Ståhlbröst A. Living lab - an open and citizencentric approach for innovation. Int J Innov Reg Dev. 2015;1(4): 356-370.

19. Almirall E, Lee M, Wareham J. Mapping living labs in the landscape of innovation methodologies. Technology Innovation Management Review. 2012;2(9):12-18.

20. Fulmer T. Geriatric Nursing 2.0! J Am Geriatr Soc. 2015;63(7): 1453-1458.

21. Bass BM, Stogdill RM, Stogdill RM. Bass \& Stogdill's Handbook of Leadership: Theory, Research, and Managerial Applications. 3rd ed. New York, NY; London, UK: Free Press; Collier Macmillan; 1990.

22. Dionne SD, Yammarino FJ, Atwater LE, Spangler WD. Transformational leadership and team performance. Journal of organizational change management. 2004;17(2):177-193.

23. Morin D, Ramelet A-S, Shaha M. Vision romande de la pratique infirmière avancée [Advanced practice nursing: vision in Roman Switzerland]. Rech Soins Infirm. 2013;(115):49-58. French. 
24. Latimer J. Critical constructionism in nursing research. In: Holstein JA, Gubrium JF, editors. Handbook of Constructionist Research. New York, NY: The Guilford Press; 2008:153-170.

25. Banerjee S. Multimorbidity - older adults need health care that can count past one. Lancet. 2015;385(9968):587-589.

26. Rodriguez-Mañas L, Fried LP. Frailty in the clinical scenario. Lancet. 2015;385(9968):e7-e9.

27. Ball MM, Perkins MM, Whittington FJ, et al. Managing decline in assisted living: the key to aging in place. J Gerontol B Psychol Sci Soc Sci. 2004;59(4):S202-S212.

28. Graafmans J, Taipale V. Gerontechnology. A sustainable investment in the future. Stud Health Technol Inform. 1998;48:3-6.

29. Winthereik JCT, Malmborg L, Andersen TB. Living labs as a methodological approach to universal access in senior design. In: Stephanidis C, editor. Universal Access in Human-Computer Interaction. Addressing Diversity. Berlin, Germany: Springer; 2009:174-183.

30. Goff K. Senior to senior: living lessons. Educ Gerontol. 2004; 30(3):205

31. Cody WK. Philosophical and Theoretical Perspectives for Advanced Nursing Practice. Burlington, MA: Jones \& Bartlett Learning; 2013.

32. Fawcett J, Downs FS. The Relationship of Theory and Research. Philadelphia, PA: Davis Company; 1992.

33. Gittell JH. High Performance Healthcare Using the Power of Relationships to Achieve Quality, Efficiency and Resilience. 1st ed. New York, NY: McGraw-Hill; 2009.

34. Esteban Millat A, Haselmayer S, Rasmussen JH. Connected Cities: Your 256 Billion Euro Dividend: How Innovation in Services and Mobility Contributes to the Sustainability of Our Cities: A Handbook. London, UK: Design London, Royal College of Art; 2010.

35. WeDO. Cadre européen de Qualité pour les services de soins et d'accompagnement aux personnes âgées. Brussels, Belgium: WeDO; 2012.

36. Hacker K. Community-Based Participatory Research. Thousand Oaks, CA: SAGE; 2013.

37. Brown J, Isaacs D. The World Café: Shaping Our Futures Through Conversations that Matter. 1st ed. San Francisco, CA: Berrett-Koehler Publishers; 2005.

38. Gergen KJ. Toward Transformation in Social Knowledge. 3rd ed. London, UK: Springer; 2014.

39. Richard L, Barthélémy L, Tremblay M-C, Pin S, Gauvin L. Interventions de prévention et promotion de la santé pour les aînés: modèle écologique: guide d'aide à l'action franco-québécois. Saint-Denis: Inpes, coll. Santé en action; 2013.

40. Israel BA, Eng E, Schulz AJ, Parker EA. Methods for CommunityBased Participatory Research for Health. 2nd ed. San Francisco, CA: Jossey-Bass; 2013.
41. World Health Organization, International Network for the Prevention of Elder Abuse. Missing Voices: Views of Older Persons on Elder Abuse. Geneva, Switzerland: WHO; 2002.

42. McNamee S, Hosking DM. Research and Social Change: A Relational Constructionist Approach. 1st ed. New York, NY: Routledge; 2012.

43. Cooperrider DL, Whitney DK, Stavros JM. Appreciative Inquiry Handbook: For Leaders of Change. Brunswick, OH; San Francisco, CA: Crown Custom Publishing; Berrett-Koehler Publishers; 2008.

44. Clandinin DJ. Engaging in Narrative Inquiry. 1st ed. Walnut Creek, CA: Left Coast Press; 2013.

45. World Health Organization. Global Age-Friendly Cities: A Guide. Geneva, Switzerland: WHO; 2007.

46. Prince M, Albanese E, Guerchet M. World Alzheimer Report 2014. London, UK: Alzheimer's Disease International (ADI); 2014

47. Cornwell EY, Waite LJ. Social disconnectedness, perceived isolation, and health among older adults. J Health Soc Behav. 2009;50(1):31-48.

48. Rantz MJ, Marek KD, Aud M, et al. A technology and nursing collaboration to help older adults age in place. Nurs Outlook. 2005;53(1): $40-45$.

49. Kleffel D. Environmental paradigms: moving towards an ecocentric perspective. In: Cody WK, editor. Philosophical and Theoretical Perspectives for Advanced Nursing Practice. 5th ed. Sudbury, MA: Jones \& Bartlett Publishers; 2013:149-160.

50. Arlanian-Engoren C, Hicks Frank D, Whall AL, Algase DL. An ontological view of advanced practice nursing. In: Cody WK, editor. Philosophical and Theoretical Perspectives for Advanced Nursing Practice. Sudbury, MA: Jones \& Bartlett Publishers; 2013:73-80.

51. fares.ch [homepage on the Internet]. Fédération des Associations des retraités et de l'entraide en Suisse. 2015. Available from: www.fares.ch/. Accessed August 28, 2015.

52. Edwards N. Improving Hospitals and Health Services Delivery. Copenhagen, Denmark: WHO, Regional Office for Europe; 2012.

53. Randall WL, McKim AE. Reading Our Lives: The Poetics of Growing Old. 1st ed. Oxford, UK: Oxford University Press; 2008.

54. Vygotskii LS, Rieber RW. The Collected Works of L.S. Vygotsky. Vol 4. New York, NY: Plenum; 1997.

55. Doyle M, Timonen V. Lessons from a community-based participatory research project: older people's and researchers' reflections. Res Aging. 2009;32(2):244-263.

56. Thiesen Winthereik J, Malmborg L, Andersen T. Living labs as a methodological approach to universal access in senior design. In: Stephanidis C, editor. Universal Access in Human-Computer Interaction. Addressing Diversity. Vol. 5614. Berlin, Germany: Springer; 2009:174-183.
Clinical Interventions in Aging

\section{Publish your work in this journal}

Clinical Interventions in Aging is an international, peer-reviewed journal focusing on evidence-based reports on the value or lack thereof of treatments intended to prevent or delay the onset of maladaptive correlates of aging in human beings. This journal is indexed on PubMed Central, MedLine,

\section{Dovepress}

CAS, Scopus and the Elsevier Bibliographic databases. The manuscript management system is completely online and includes a very quick and fair peer-review system, which is all easy to use. Visit http://www.dovepress. com/testimonials.php to read real quotes from published authors. 